\title{
Pharmacokinetic Profiles and Pharmacodynamic Effects for Methylone and Its Metabolites in Rats
}

\author{
Joshua S Elmore', Ora Dillon-Carter', John S Partilla', Kayla N Ellefsen ${ }^{2,3}$, Marta Concheiro $^{2,4}$, Masaki Suzuki ${ }^{5}$, \\ Kenner C Rice ${ }^{5}$, Marilyn A Huestis ${ }^{2}$ and Michael H Baumann*, \\ 'Designer Drug Research Unit, Intramural Research Program, National Institute on Drug Abuse, National Institutes of Health, Baltimore, MD, USA; \\ ${ }^{2}$ Chemistry \& Drug Metabolism Section, Intramural Research Program, National Institute on Drug Abuse, National Institutes of Health, Baltimore, \\ MD, USA; ${ }^{3}$ Program in Toxicology, University of Maryland at Baltimore, Baltimore, MD, USA; ${ }^{4}$ Department of Sciences, John Jay College of Criminal \\ Justice, City University of New York, New York, NY, USA; ${ }^{5}$ Drug Design and Synthesis Section, Intramural Research Program, National Institute on \\ Drug Abuse, National Institutes of Health, Baltimore, Maryland, USA
}

\begin{abstract}
3,4-Methylenedioxy-N-methylcathinone (methylone) is a new psychoactive substance and the $\beta$-keto analog of 3,4-methylenedioxy- $N$ methylamphetamine (MDMA). It is well established that MDMA metabolism produces bioactive metabolites. Here we tested the hypothesis that methylone metabolism in rats can form bioactive metabolites. First, we examined the pharmacokinetics (PKs) of methylone and its metabolites after subcutaneous (sc) methylone administration $(3,6,12 \mathrm{mg} / \mathrm{kg}$ ) to male rats fitted with intravenous (iv) catheters for repeated blood sampling. Plasma specimens were assayed by liquid chromatography tandem mass spectrometry to quantify methylone and its phase I metabolites: 3,4-methylenedioxycathinone (MDC), 3,4-dihydroxy-N-methylcathinone (HHMC), and 4-hydroxy-3-methoxy-Nmethylcathinone (HMMC). The biological activity of methylone and its metabolites was then compared using in vitro transporter assays and in vivo microdialysis in rat nucleus accumbens. For the PK study, we found that methylone and MDC peaked early $\left(T_{\max }=15-45 \mathrm{~min}\right)$ and were short lived $\left(t_{1 / 2}=60-90 \mathrm{~min}\right)$, while HHMC and HMMC peaked later $\left(T_{\max }=60-120 \mathrm{~min}\right)$ and persisted $\left(t_{1 / 2}=120-180 \mathrm{~min}\right)$. Areaunder-the-curve values for methylone and MDC were greater than dose-proportional, suggesting non-linear accumulation. Methylone produced significant locomotor activation, which was correlated with plasma methylone, MDC, and HHMC concentrations. Methylone, MDC, and HHMC were substrate-type releasers at monoamine transporters as determined in vitro, but only methylone and MDC $(\mathrm{I}, 3 \mathrm{mg} / \mathrm{kg}$, iv) produced significant elevations in brain extracellular dopamine and 5-HT in vivo. Our findings demonstrate that methylone is extensively metabolized in rats, but MDC is the only centrally active metabolite that could contribute to overall effects of the drug in vivo. Neuropsychopharmacology (2017) 42, 649-660; doi:I 0. I038/npp.20I6.2 I3; published online 26 October 2016
\end{abstract}

\section{INTRODUCTION}

Synthetic cathinones are a class of new psychoactive substances with structural and pharmacological similarity to amphetamines (Glennon, 2014). Various cathinone analogs appeared in the United States recreational drug market during 2010 and 2011 and were sold under false pretenses as 'bath salts', 'plant food' or 'research chemicals' to circumvent legislative and regulatory efforts (Baumann et al, 2013). The cathinones most commonly found in early bath salts included 3,4-methylenedioxypyrovalerone, ( \pm )-3,4-methylenedioxy- $N$-methylcathinone $\mathrm{HCl}$ (methylone) and 4-methyl- $N$-methylcathinone. These substances were placed into emergency schedule I control in 2011 by the

*Correspondence: Dr MH Baumann, Designer Drug Research Unit, Intramural Research Program, National Institute on Drug Abuse, National Institutes of Health, 333 Cassell Drive, Suite 4400, Baltimore, MD 21224, USA, Tel: +I 443 740-2660, Fax: +I 443740 224I, E-mail: mbaumann@mail.nih.gov

Received 19 April 2016; revised 5 September 2016; accepted 10 September 2016; accepted article preview online 23 September 2016
US Drug Enforcement Administration (DEA), and were later permanently scheduled (Drug Enforcement Administration DoJ, 2011, 2013). Despite these legislative efforts, reports by the DEA revealed that the prevalence of methylone increased from 2011 to 2013, and as of 2014, methylone was encountered as often as the club drug 3,4-methylenedioxy$\mathrm{N}$-methylamphetamine (MDMA) (NFLIS Special Report, 2014; NFLIS 2014 Annual Report). Recreational users take methylone for its euphoric and stimulant properties, but it can cause life-threatening adverse effects, including hyperthermia, seizures, and kidney damage; its use has led to several analytically confirmed fatalities (Barrios et al, 2015; Carbone et al, 2013; Cawrse et al, 2012; Kovacs et al, 2012; Ridpath et al, 2014; Warrick et al, 2012).

From a pharmacological perspective, methylone exerts its effects by acting as a substrate at the plasma membrane transporters for dopamine (DAT), norepinephrine (NET), and 5-HT (SERT), thereby inducing non-exocytotic release of these monoamine transmitters (Baumann et al, 2012; Eshleman et al, 2013; Simmler et al, 2013). In vivo studies in rats demonstrate that methylone increases extracellular 
concentrations of dopamine and 5-HT in the brain, with greater effects on 5-HT (Baumann et al, 2012; Schindler et al, 2016). The mechanism of action for methylone resembles that of MDMA, which is not surprising considering methylone is the $\beta$-keto analog of MDMA. It is notable that MDMA is metabolized by hepatic mechanisms in rats and humans (de la Torre and Farre, 2004), and its bioactive metabolites may contribute to the profile of drug effects in vivo (Concheiro et al, 2014; Schindler et al, 2014). Moreover, MDMA displays non-linear pharmacokinetics (PKs) characterized by increases in plasma drug concentrations that are greater than dose-proportional (Baumann et al, 2009; Chu et al, 1996; de la Torre et al, 2000).

Few studies have examined methylone metabolism and PKs in vivo. Kamata et al (2006) first evaluated methylone metabolism by determining parent and metabolite concentrations in urine from rats and humans exposed to methylone. These investigators showed that methylone is metabolized in a manner akin to MDMA involving two major pathways (Figure 1): (1) O-demethylenation to form ( \pm )-3,4-dihydroxy- $N$-methylcathinone (HHMC) followed by $O$-methylation to form $( \pm)$-4-hydroxy-3methoxy- $N$-methylcathinone (HMMC) and (2) $N$-demethylation to produce $( \pm)$-3,4-methylenedioxycathinone (MDC) (Kamata et al, 2006). Methylone is primarily biotransformed by cytochrome p450 2D6 (CYP2D6) in humans, the same isoform responsible for metabolism of MDMA (Pedersen et al, 2013). Lopez-Arnau et al (2013) evaluated methylone $\mathrm{PK}$ and pharmacodynamic effects in rats and found that methylone exhibits rapid kinetics, with peak blood concentrations occurring $30 \mathrm{~min}$ after oral administration, and readily crosses the blood-brain barrier (Lopez-Arnau et al, 2013). In the study of Lopez-Arnau et al (2013), methylone concentrations in plasma correlated with locomotor activation, although the authors speculated that metabolites may also be bioactive. Importantly, the plasma PK profiles for the metabolites of methylone have not been reported, and the potential bioactivity of methylone metabolites has yet to be systematically evaluated.

Ellefsen et al (2015) reported a highly sensitive validated assay for the quantification of methylone, MDC, HHMC, and HMMC using liquid chromatography tandem mass spectrometry (LC-MS/MS) (Ellefsen et al, 2015). In the present study, we utilized this new analytical method to test the hypothesis that methylone is metabolized in rats to form bioactive metabolites. In particular, we examined plasma concentrations of methylone and its metabolites after systemic administration of methylone at multiple doses $(3,6$, and $12 \mathrm{mg} / \mathrm{kg})$. We employed the subcutaneous (sc) route of administration for the PK studies to allow for the comparison of our data with the results of others who examined pharmacological effects of sc methylone in rats (Baumann et al, 2012; Grecco and Sprague, 2016; Kiyatkin et al, 2015; Lopez-Arnau et al, 2014). Our experiments employed freely moving rats fitted with indwelling jugular catheters, which enabled repeated assessment of $\mathrm{PK}$ and pharmacodynamic end points in the same individuals. Next we examined the neurobiological effects of methylone and its metabolites using in vitro transporter release assays and in vivo microdialysis in the rat brain. Overall, our findings demonstrate that methylone is extensively metabolized after systemic administration and displays non-linear

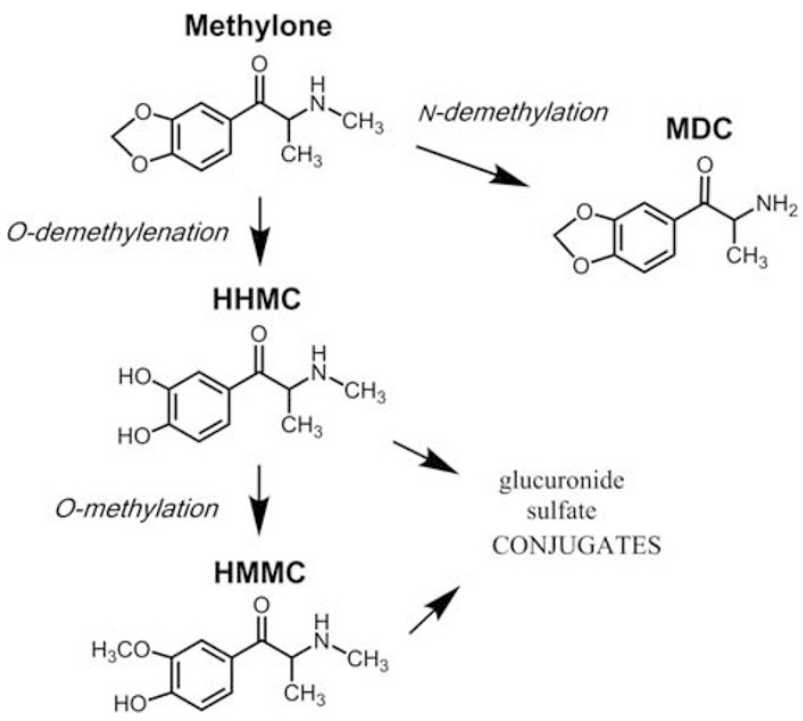

Figure I Pathways of methylone metabolism. Methylone, 3,4-methylenedioxy-N-methylcathinone; MDC, 3,4-methylenedioxycathinone; HHMC, 3,4-dihydroxy-N-methylcathinone; HMMC, 4-hydroxy-3-methoxy-Nmethylcathinone.

accumulation in plasma. In addition, MDC and HHMC are potent substrates at monoamine transporters in vitro, but only MDC induces centrally mediated neurochemical effects in vivo.

\section{MATERIALS AND METHODS}

\section{Drugs and Reagents}

( \pm )-3,4-Methylenedioxy- $N$-methylcathinone $\mathrm{HCl}$ (methylone) was obtained from the National Institute on Drug Abuse (NIDA) Drug Supply Program (Rockville, MD, USA). $\mathrm{MDC} \mathrm{HCl}, \mathrm{HHMC} \mathrm{HBr}$, and $\mathrm{HMMC} \mathrm{HCl}$ were synthesized as previously described (Ellefsen et al, 2015). [ $\left.{ }^{3} \mathrm{H}\right] 1$-methyl4-phenylpyridinium $\left(\left[{ }^{3} \mathrm{H}\right] \mathrm{MPP}+\right.$, specific activity $=85 \mathrm{Ci} /$ mmol) was purchased from American Radiolabeled Chemicals (St Louis, MO, USA), whereas $\left[{ }^{3} \mathrm{H}\right]$ serotonin $\left(\left[{ }^{3} \mathrm{H}\right] 5-\mathrm{HT}\right.$, specific activity $=20 \mathrm{Ci} / \mathrm{mmol})$ was purchased from Perkin Elmer (Shelton, CT, USA). All other chemicals and reagents required for LC-MS/MS, in vitro transporter assays, in vivo microdialysis methods, and high-performance liquid chromatography with electrochemical detection (HPLC-ECD) were obtained from Sigma-Aldrich (St Louis, MO, USA) unless otherwise noted.

\section{Animals and Surgery}

Male Sprague-Dawley rats weighing 250-300 g were grouphoused (lights on: 0700-1900 hours) under controlled temperature $\left(22 \pm 2{ }^{\circ} \mathrm{C}\right)$ and humidity $(45 \% \pm 5 \%)$ with free access to food and water. Experiments were performed in accordance with the National Institutes of Health Guide for the Care and Use of Laboratory Animals. Vivarium facilities were fully accredited by the Association for Assessment and Accreditation of Laboratory Animal Care, and study procedures were approved by the NIDA IRP Animal Care and Use Committee. After 2 weeks of acclimation to the 
vivarium, rats were used for tissue harvest or subjected to surgical procedures and subsequently used for experiments. A total of 75 rats were used for these studies: 25 for the PK experiments, 16 for the in vitro transporter assays, and 34 for the in vivo microdialysis experiments.

For the PK experiments, rats were anesthetized with $60 \mathrm{mg} / \mathrm{kg}$ intraperitoneal (ip) sodium pentobarbital. Each rat received a surgically implanted IPTT-300 transponder (Bio Medic Data Systems, Seaford, DE, USA) to facilitate noninvasive measurement of body temperature via a handheld radio frequency reader system. Transponders were $14 \times 2 \mathrm{~mm}^{2}$ cylinders and were implanted sc posterior to the shoulder blades via a sterile guide needle. Immediately after transponder implantation, each rat received a surgically implanted catheter in the right jugular vein (Baumann et al, 2012). In brief, the proximal Silastic end of the catheter was inserted into the right jugular vein and advanced to the atrium, whereas the distal vinyl end was exteriorized on the nape and plugged with a metal stylet. Animals were individually housed postoperatively and allowed 7-10 days for recovery.

For the in vivo microdialysis experiments, rats were anesthetized with $60 \mathrm{mg} / \mathrm{kg}$ ip sodium pentobarbital. Each rat received a surgically implanted jugular catheter as described above. Immediately after the catheter surgery, rats were placed into a stereotaxic apparatus and a CMA12 intracerebral guide cannula (Harvard Apparatus, Holliston, MA, USA) was implanted above the nucleus accumbens, according to the stereotaxic coordinates: $1.6 \mathrm{~mm}$ lateral and $1.6 \mathrm{~mm}$ anterior to bregma, and $6.0 \mathrm{~mm}$ below the surface of the dura. Guide cannulae were secured to the skull using stainless steel anchor screws and dental acrylic. Animals were individually housed postoperatively and allowed 7-10 days for recovery.

\section{PK Experiments}

Rats were moved to the testing room in their home cages and given $1 \mathrm{~h}$ to acclimate. Feeding trays were removed, and wire lids were placed atop the cages. Polyethylene extension tubes $(30 \mathrm{~cm})$ were filled with sterile saline, connected to iv catheters, and threaded outside the cages. Catheters were flushed with $0.3 \mathrm{ml}$ of $48 \mathrm{IU} / \mathrm{ml}$ heparin saline to facilitate blood withdrawal. Groups of rats received sc injections of 0 (saline), 3, 6, or $12 \mathrm{mg} / \mathrm{kg}$ methylone in a volume of $1 \mathrm{ml} / \mathrm{kg}$. Blood specimens $(0.30 \mathrm{ml})$ were withdrawn immediately before injection and at $15 \mathrm{~min}, 30 \mathrm{~min}, 1,2,4$, and $8 \mathrm{~h}$ thereafter. Blood was collected into $1 \mathrm{ml}$ syringes, transferred to $1.5 \mathrm{ml}$ plastic tubes fortified with $5 \mu \mathrm{l}$ of sodium metabisulfite $(250 \mathrm{nM})$ and $5 \mu \mathrm{l}$ heparin (1000 IU), and centrifuged for $10 \mathrm{~min}$ at $3000 \mathrm{rpm}$; plasma was decanted and stored at $-80^{\circ} \mathrm{C}$. An equal volume of sterile saline was infused after each blood withdrawal to maintain volume and osmotic homeostasis.

Behavior was monitored for a period of $1 \mathrm{~min}$ before blood sampling, and each rat was assigned a locomotor activity score based upon the following parameters: $1=$ asleep or still; $2=$ in-place activities; $3=$ locomotion, rearing, or sniffing; $4=$ any two (locomotion, rearing, or sniffing); $5=10 \mathrm{~s}$ of continuous sniffing without locomotion or rearing; $6=10 \mathrm{~s}$ of continuous sniffing with locomotion or rearing; $7=5 \mathrm{~s}$ of patterned sniffing; $8=10 \mathrm{~s}$ of patterned sniffing. Patterned sniffing was defined as any repeated head motion (eg, up and down 'head bobbing') that occurred simultaneously with sniffing behavior. After observation, core temperatures were measured via a handheld radio frequency scanner, which acquired data via the implanted transponder.

\section{Quantification of Methylone and Metabolites in Plasma}

Plasma specimens were analyzed using LC-MS/MS, as previously described (Ellefsen et al, 2015). Briefly, $10 \mu \mathrm{l}$ of $\beta$-glucuronidase was added to $100 \mu \mathrm{l}$ of plasma to hydrolyze metabolite conjugates. Specimens were incubated at $50{ }^{\circ} \mathrm{C}$ for $60 \mathrm{~min}$. Twenty microliters of $1 \mathrm{mg} / \mathrm{ml} 4$-methylcatechol and $10 \mu \mathrm{l}$ of concentrated perchloric acid were added, and the tubes were centrifuged at $15000 \mathrm{~g}$ for $10 \mathrm{~min}$. Supernatants were then loaded onto preconditioned cation exchange solidphase-extraction cartridges and washed with $1 \mathrm{M}$ acetic acid $(500 \mu \mathrm{l})$ and methanol $(500 \mu \mathrm{l})$ before eluting with $5 \%$ ammonium hydroxide in methylene chloride/isopropanol $(60: 40 \mathrm{v} / \mathrm{v})$. Extracts were evaporated to dryness under nitrogen for $20 \mathrm{~min}$ at $40^{\circ} \mathrm{C}$ after adding $50 \mu \mathrm{l}$ of acidic methanol $(1 \% \mathrm{HCl})$ to prevent analyte loss, before reconstitution in $200 \mu \mathrm{l}$ of mobile phase A ( $0.1 \%$ formic acid in water).

Specimens were transferred into autosampler vials and LC-MS/MS analysis was performed on a Shimadzu liquid chromatography (LC) system (Columbia, MD, USA) coupled with an ABSciex 3200 QTrap mass spectrometer with a Turbolon Spray source (Foster City, CA, USA). Chromatographic separation was performed with a Synergi Polar-RP $100 \mathrm{~A}, 100 \times 2 \mathrm{~mm}^{2}, 4 \mu \mathrm{m}$ column (Phenomenex, Torrance, CA, USA) with gradient elution performed with $0.1 \%$ formic acid in water (mobile phase A) and $0.1 \%$ formic acid in acetonitrile (mobile phase B). Mass spectrometric data were acquired in positive electrospray ionization mode with the following source parameters: IonSpray voltage $3500 \mathrm{~V}$; temperature $600{ }^{\circ} \mathrm{C}$; curtain gas 50; ion source gas 150 and ion source gas 230. Analytes were determined by two multiple reaction monitoring transitions. During method development, it was noted that HHMC exhibited high bias and imprecision, thus HHMC concentrations reported here are considered semiquantitative.

\section{In Vitro Transporter Release Assays}

Rats were killed by $\mathrm{CO}_{2}$ narcosis, and the brains were processed to yield synaptosomes (Rothman et al, 2001). One whole brain minus caudate and cerebellum (for SERT and NET assays) or one pair of caudates (for DAT assays) was diluted in $10 \mathrm{ml}$ of ice-cold $10 \%$ sucrose containing $1 \mu \mathrm{M}$ reserpine. Tissue was homogenized using a Potter-Elvehjem homogenizer, centrifuged at $1000 \mathrm{~g}$ for $10 \mathrm{~min}$ at $4{ }^{\circ} \mathrm{C}$, and supernatants (ie, synaptosomal preparations) were retained on ice. Supernatants were diluted with sucrose solution to yield protein concentrations of $900 \mu \mathrm{g} / \mathrm{ml}$ for SERT and NET assays and $90 \mu \mathrm{g} / \mathrm{ml}$ for DAT assays. In vitro release assays were conducted using $\left[{ }^{3} \mathrm{H}\right] \mathrm{MPP}^{+}$as the radiolabeled substrate for DAT and NET, while using $\left[{ }^{3} \mathrm{H}\right] 5-\mathrm{HT}$ as the radiolabeled substrate for SERT.

Synaptosomes were incubated to steady state in a polypropylene beaker, with stirring at $25^{\circ} \mathrm{C}$, in Krebs phosphate buffer ( $\mathrm{pH} 7.4$ ), which contained $1 \mu \mathrm{M}$ reserpine 
and either $5 \mathrm{nM} \quad\left[{ }^{3} \mathrm{H}\right] \mathrm{MPP}^{+}$or $5 \mathrm{nM} \quad\left[{ }^{3} \mathrm{H}\right] 5-\mathrm{HT}$. To commence the assay, $850 \mu \mathrm{l}$ of preloaded synaptosomes were added to polystyrene test tubes or 96-well plates that contained $150 \mu \mathrm{l}$ test drug in uptake buffer plus $1 \mathrm{mg} / \mathrm{ml}$ bovine serum albumin. Eight-point dilution curves, with doses ranging from 10 to $10000 \mathrm{nM}$, were performed in triplicate on three separate occasions for each test drug. After $30 \mathrm{~min}\left(\left[{ }^{3} \mathrm{H}\right] \mathrm{MPP}^{+}\right.$assays) or $5 \mathrm{~min}\left(\left[{ }^{3} \mathrm{H}\right] 5-\mathrm{HT}\right.$ assays), the release reaction was terminated by dilution with $4 \mathrm{ml}$ wash buffer $(10 \mathrm{mM}$ Tris- $\mathrm{HCl} \mathrm{pH} 7.4$ containing $0.9 \% \mathrm{NaCl}$ at $25^{\circ} \mathrm{C}$ ) followed by rapid vacuum filtration over Whatman GF/B filters using a Brandel cell harvester (Brandel, Gaithersburg, MD, USA). Filters were rinsed twice with $4 \mathrm{ml}$ wash buffer and dried under vacuum. The retained tritium was counted by a liquid scintillation counter at $40 \%$ efficiency after an overnight extraction in $0.6 \mathrm{ml}$ scintillation cocktail. It is important to note that the amount of tritium retained is inversely proportional to the extent of release from synaptosomes; that is, a lower amount of retained tritium reflects a higher degree of transporter-mediated release. Drug potency is expressed as the molar concentration required to evoke $50 \%$ of maximal release $\left(\mathrm{EC}_{50}\right)$, where maximal release is defined in the presence of saturating concentrations of the non-specific transporter substrate, tyramine: $10 \mu \mathrm{M}$ tyramine for DAT and NET assays or $100 \mu \mathrm{M}$ tyramine for SERT assays.

\section{In Vivo Microdialysis Procedures}

In vivo microdialysis sampling was carried out as previously described, with minor modifications (Baumann et al, 2012). On the evening before an experiment, rats were moved to the testing room. A plastic collar was placed around the neck of each rat, a dialysis probe (CMA/12, Harvard Apparatus) was inserted into the guide cannula, and an extension tube was attached to the indwelling jugular catheter. The probe exchange surface was $2 \times 0.5 \mathrm{~mm}$. Each rat was placed into its own activity field arena and connected to a tethering system, which allowed motor activity within the container. Probes were perfused overnight with artificial cerebrospinal fluid pumped at a flow rate of $0.6 \mu \mathrm{l} / \mathrm{min}$. On the next morning, dialysate samples were collected at 20 min intervals. Samples were immediately assayed for dopamine and 5HT by HPLC-ECD. Chromatographic data were acquired online and exported to an Empower software system (Waters Associates, Milford, MA, USA) for peak amplification, integration, and analysis.

Rats were randomly assigned to groups receiving either drug (methylone, MDC, HHMC, or HMMC) or saline injections. Once three stable baseline samples were obtained, rats received two sequential iv injections of drug, $1 \mathrm{mg} / \mathrm{kg}$ at time 0 , followed by $3 \mathrm{mg} / \mathrm{kg} 60 \mathrm{~min}$ later. Control rats received sequential iv injections of saline $(1 \mathrm{ml} / \mathrm{kg})$ according to the same schedule. We employed the iv route of administration for the microdialysis studies because this route affords a rapid assessment of drug effects while minimizing drug metabolism. Furthermore, the iv doses determined in the present study can be used as a guide for subsequent iv self-administration experiments if warranted. Microdialysis samples were collected every $20 \mathrm{~min}$ throughout the postinjection period for $120 \mathrm{~min}$. At the end of the experiment, rats were killed with $\mathrm{CO}_{2}$ and decapitated. Brain sections were examined to verify placement of microdialysis probe tips within the nucleus accumbens. Only those rats with correct placements were included in data analyses. During the overnight acclimation period and while undergoing microdialysis, each rat was housed within a square Plexiglass arena (43 length $\times 43$ width $\times 43$ height $\left(\mathrm{cm}^{3}\right)$ ) equipped with a TruScan activity monitoring system (Coulbourn Instruments, Holliston, MA, USA), which was used to quantify horizontal locomotor activity. Horizontal locomotor activity was defined as the total distance traveled in the horizontal plane (measured in $\mathrm{cm}$ ).

\section{Data Analysis and Statistics}

Data from PK experiments, in vitro release assays, and in vivo microdialysis were tabulated, analyzed, and graphically depicted using GraphPad Prism (version 5.04; GraphPad Software, La Jolla, CA). Plasma PK data were further analyzed using WinNonlin (version 6.3; Pharsight, Mountain View, CA) to determine non-compartmental PK constants. To evaluate possible non-linearity for plasma analyte concentrations, area-under-the-curve (AUC) values following $3 \mathrm{mg} / \mathrm{kg}$ were multiplied by 2 and 4 to calculate expected AUCs for 6 and $12 \mathrm{mg} / \mathrm{kg}$ doses, respectively. The expected values from the 6 and $12 \mathrm{mg} / \mathrm{kg}$ doses were compared with observed results by two-way ANOVA (treatment $\times$ condition), followed by Bonferroni's post hoc tests. Dose-response data from in vitro release experiments were subjected to nonlinear regression and expressed as the percentage of maximal release. Potency estimates are given as $\mathrm{EC}_{50}$ values determined from the fitted curves. Behavioral data were analyzed using a non-parametric Friedman's test followed by Dunn's multiple comparison test, whereas temperature data were evaluated by two-way analysis of variance (treatment $\times$ time), followed by Bonferroni's post hoc test. Neurochemical and locomotor data from the microdialysis experiments were analyzed by two-way analysis of variance (treatment $\times$ time) followed by Bonferroni's post hoc test. $p<0.05$ was considered the minimal criterion for statistical significance.

\section{RESULTS}

\section{PKs of Methylone and its Metabolites}

Figure 2 depicts time-concentration profiles for plasma methylone, MDC, HHMC, and HMMC after sc injection of 3, 6, and $12 \mathrm{mg} / \mathrm{kg}$ methylone. The PK constants derived from the data depicted in Figure 2 are presented in Table 1. Methylone plasma concentrations increased in a dose-related manner. $C_{\max }$ values for methylone were 620,1410 , and $3170 \mu \mathrm{g} / \mathrm{l}$ for the 3,6 , and $12 \mathrm{mg} / \mathrm{kg}$ doses, while corresponding AUC values were 26 800, 68300 and $201000 \mathrm{~min} \times \mu \mathrm{g} / \mathrm{l}$. Methylone exhibited rapid kinetics with a $T_{\max }$ value of $15 \mathrm{~min}$ after all doses and $t_{1 / 2}$ values of 48,57 , and $66 \mathrm{~min}$ for 3 , 6 , and $12 \mathrm{mg} / \mathrm{kg}$, respectively. $\mathrm{MDC} C_{\max }$ values were about 10-fold lower than those for methylone across all doses, while MDC AUC values were roughly three times lower when compared with methylone. MDC exhibited slower kinetics than methylone, with $T_{\max }$ values of 30,35 , and $45 \mathrm{~min}$ and $t_{1 / 2}$ values of 64,70 , and $88 \mathrm{~min}$ for 3,6 , and $12 \mathrm{mg} / \mathrm{kg}$ methylone. 

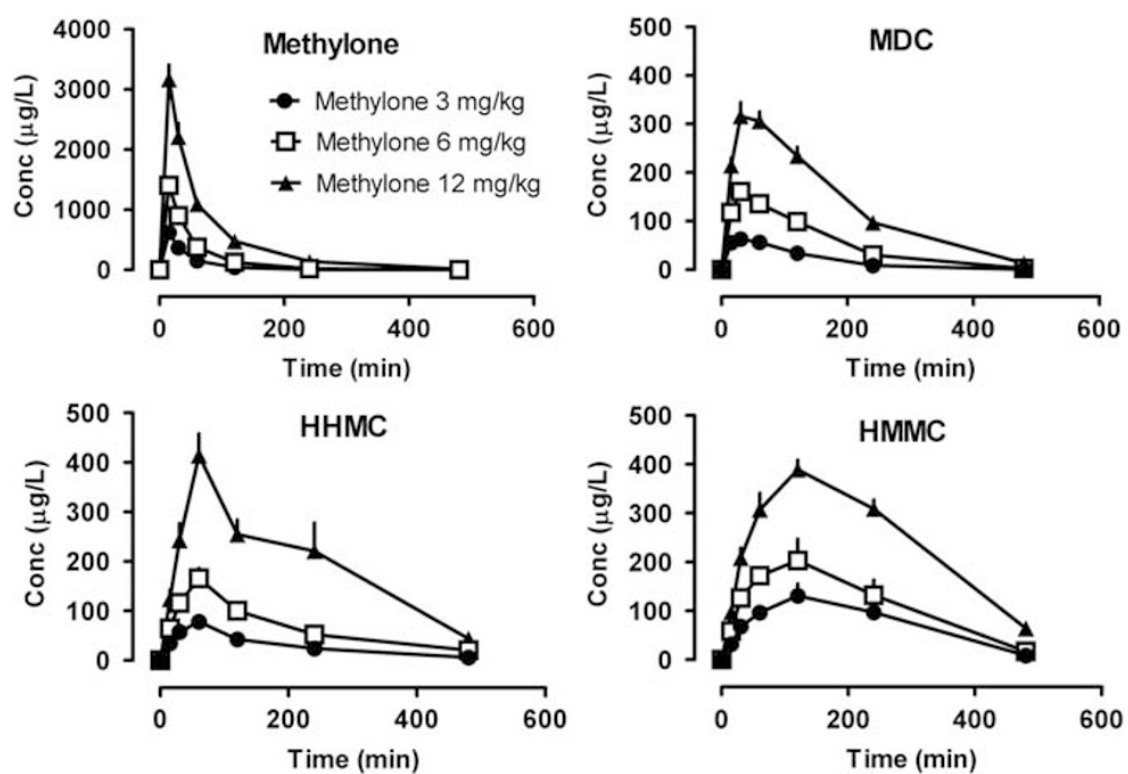

Figure 2 Concentration-time profiles for methylone, MDC, HHMC, and HMMC after sc administration of methylone. Data are mean \pm SEM for $N=6 / 7$ rats per group. Rats received a sc dose of 0 (saline), 3, 6, or 12 mg/kg methylone, and blood was collected at I5, 30, 60, I 20, 240, and 480 min postinjection. Plasma was separated and analyzed by LC-MS/MS.

Table I Pharmacokinetic Constants (Mean \pm SEM) for Plasma Methylone, MDC, HHMC, and HMMC After sc Methylone Injection at 3, 6, or $12 \mathrm{mg} / \mathrm{kg}$ to Rats ( $\mathrm{N}=6-7$ per Group)

\begin{tabular}{|c|c|c|c|c|c|c|}
\hline Analytes & Dose (mg/kg) & $C_{\max }(\mu g / I)$ & $T_{\max }(\min )$ & AUC $(\min \times \mu g / I)$ & $t_{1 / 2}(\min )$ & $C_{\text {last }}(\mu g / I)$ \\
\hline \multirow[t]{2}{*}{ Methylone } & 3 & $620 \pm 83$ & 15 & $26800 \pm 3600$ & $48 \pm 12$ & $3.5 \pm 2.4$ \\
\hline & 6 & $1410 \pm 95$ & 15 & $68300 \pm 6500$ & $57 \pm 3$ & $1.6 \pm 0.7$ \\
\hline \multirow[t]{2}{*}{$\mathrm{MDC}$} & 3 & $66 \pm 8$ & $30 \pm 15$ & $8550 \pm 1600$ & $64 \pm 7$ & $2.4 \pm 3.0$ \\
\hline & 6 & $163 \pm 38$ & $35 \pm 12$ & $24000 \pm 3200$ & $70 \pm 4$ & $2.6 \pm 0.6$ \\
\hline \multirow{2}{*}{$H H M C^{a}$} & 6 & $167 \pm 48$ & $55 \pm 12$ & $30200 \pm 5800$ & $166 \pm 47$ & $20.5 \pm 6.6$ \\
\hline & 12 & $414 \pm 110$ & $70 \pm 24$ & $86300 \pm 29000$ & $145 \pm 23$ & $43.9 \pm 8.7$ \\
\hline \multirow[t]{3}{*}{ HMMC } & 3 & $139 \pm 56$ & $120 \pm 60$ & $32300 \pm 12000$ & $97 \pm 28$ & $8.6 \pm 1.6$ \\
\hline & 6 & $223 \pm 93$ & $90 \pm 33$ & $50500 \pm 22000$ & $98 \pm 19$ & $17.1 \pm 4.7$ \\
\hline & 12 & $390 \pm 49$ & $110 \pm 24$ & $110000 \pm 12000$ & $118 \pm 19$ & $64.2 \pm 9.6$ \\
\hline
\end{tabular}

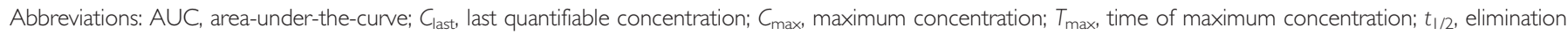
half-life.

${ }^{a}$ Results are considered semiquantitative.

HHMC plasma concentrations increased in a dose-related manner. However, it is important to note that plasma concentrations of HHMC reported here must be considered semiquantitative owing to variability when detecting this analyte, as reported in the LC-MS/MS method validation (see Ellefsen et al, 2015). $C_{\max }$ values for HHMC were 78, 167 , and $414 \mu \mathrm{g} / \mathrm{l}$, while AUC values were 12200,30200 , and $86300 \mathrm{~min} \times \mu \mathrm{g} / \mathrm{l}$ for the 3,6 , and $12 \mathrm{mg} / \mathrm{kg}$ methylone doses. HMMC had $C_{\max }$ values of 139,223 , and $390 \mu \mathrm{g} / \mathrm{l}$, and this compound was the primary metabolite as determined by AUC values, which were 32300,50500 and $110000 \mathrm{~min} \times \mu \mathrm{g} / \mathrm{l}$. HHMC and HMMC both displayed slower kinetics than methylone and MDC, with HHMC having $T_{\max }$ values of $60-70 \mathrm{~min}$ and $t_{1 / 2}$ values of 145-166 min. HMMC had $T_{\max }$ values of $90-120 \mathrm{~min}$ and $t_{1 / 2}$ values of $97-118 \mathrm{~min}$.

One of the secondary aims of our PK investigation was to examine the possibility of non-linear accumulation of methylone and its metabolites in the bloodstream. To this end, we compared the expected $v s$ observed AUC values for methylone, MDC, HHMC, and HMMC after the 6 and $12 \mathrm{mg} / \mathrm{kg}$ doses. To obtain the expected values for each analyte at the 6 and $12 \mathrm{mg} / \mathrm{kg}$ doses, the AUC values (mean \pm SEM) determined for each analyte at the $3 \mathrm{mg} / \mathrm{kg}$ dose were multiplied by a factor of 2 and 4, respectively. Figure 3 demonstrates that observed AUC values for 

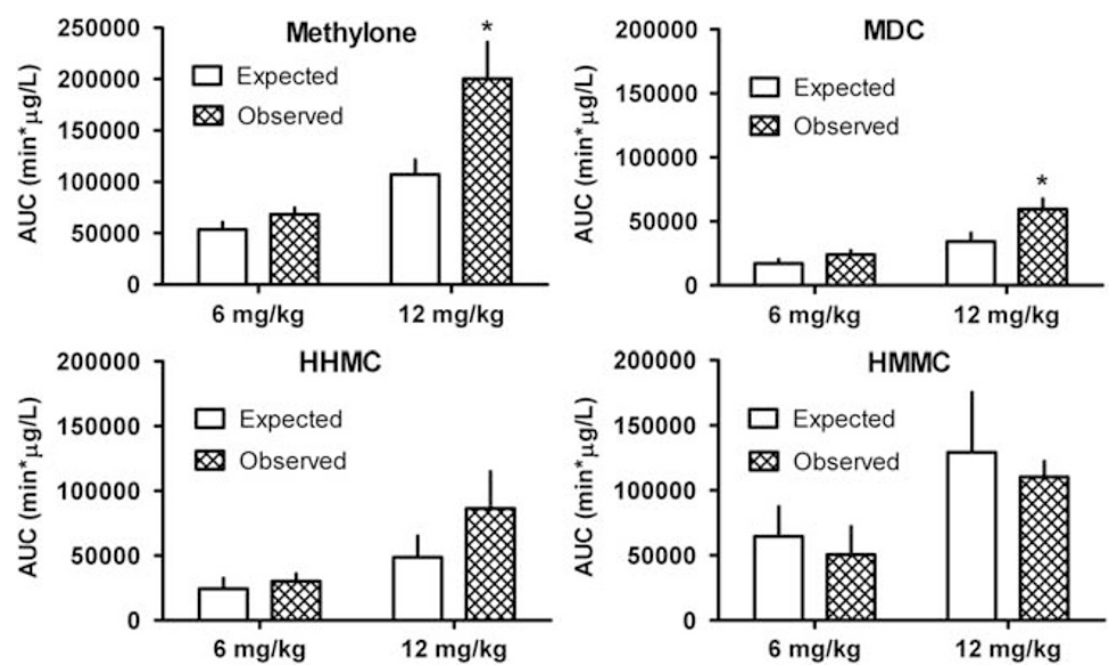

Figure 3 Comparison of expected vs observed area-under-the-curve values for methylone, MDC, HHMC, and HMMC. Expected AUCs for each analyte at 6 and $12 \mathrm{mg} / \mathrm{kg}$ methylone doses were determined by multiplying the values observed at $3 \mathrm{mg} / \mathrm{kg}$ by a factor of 2 and 4 , respectively. Data are mean \pm SEM for $N=6 / 7$ rats per group. ${ }^{*} p<0.05$ vs expected value at the corresponding dose (Bonferroni's post hoc test).
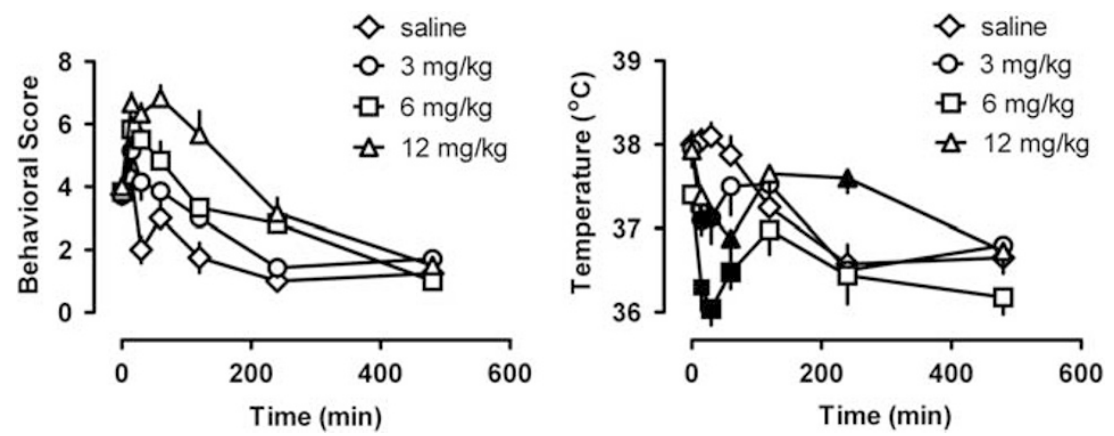

Figure 4 Pharmacodynamic data for rats receiving sc injection of 0 (saline), 3, 6, and $12 \mathrm{mg} / \mathrm{kg}$ methylone. Behavioral score and core temperature were determined at 15, 30, 60, 120, 240, and 480 min postinjection as described in Materials and Methods section. Data are mean \pm SEM for $N=6 / 7$ rats per group. For temperature data, the filled symbols represent significant effects when compared with saline-injected control rats at corresponding time points $(p<0.05$, Bonferroni's post hoc test).

methylone were greater than expected $\left(\mathrm{F}_{1,20}=3.95, p<0.01\right)$ but this effect was only significant for the $12 \mathrm{mg} / \mathrm{kg}$ dose of drug. Similarly, AUC values for MDC were greater than expected $\left(\mathrm{F}_{1,20}=2.62, p<0.01\right)$ and this difference reached significance at $12 \mathrm{mg} / \mathrm{kg}$. For HHMC and HMMC, observed AUC values were within the expected range.

\section{Pharmacodynamic Effects of Methylone}

Figure 4 depicts the effects of methylone administration on pharmacodynamic end points (ie, locomotor behavior and core body temperature) that correspond to the PK data illustrated in Figure 2. Methylone produced a significant increase in motor activation as revealed by Friedman's test $(p<0.0021)$, and a post hoc Dunn's test showed that behavioral score was significantly greater than saline control at the $12 \mathrm{mg} / \mathrm{kg}$ dose. Methylone also affected core temperature, with significant main effects of dose $\left(\mathrm{F}_{3,147}=22.95, p<0.0001\right)$, time $\left(\mathrm{F}_{6,147}=11.82, p<0.0001\right)$, and dose $\times$ time interaction $\left(\mathrm{F}_{18,147}=2.95, \quad p<0.001\right)$. Post hoc tests showed that $3 \mathrm{mg} / \mathrm{kg}$ methylone decreased temperature at 15 and $30 \mathrm{~min}$ postinjection, whereas $6 \mathrm{mg} / \mathrm{kg}$ decreased temperature at 15,30 , and 60 min postinjection. The effects of $12 \mathrm{mg} / \mathrm{kg}$ methylone on temperature were biphasic, with decreases at 15,30, and 60 min followed by increases at $240 \mathrm{~min}$ postinjection.

As PK measures and pharmacodynamic data were obtained from the same subjects, we were able to examine correlations between plasma analyte concentrations, behavioral score, and temperature. Table 2 summarizes the Pearson's correlation findings based on evaluation of the mean data depicted in Figures 2 and 4. Overall, behavioral score was positively correlated with plasma concentrations of methylone $(r=0.771, p<0.001)$, MDC $(r=0.867, p<0.001)$, and HHMC $(r=0.660, p<0.003)$ but not HMMC. By contrast, core temperature did not correlate with methylone or any of its metabolites. 


\section{Effects of Methylone and its Metabolites In Vitro}

Our correlation findings suggested that MDC and HHMC might contribute to the behavioral effects of methylone in vivo, as suggested by Lopez-Arnau et al (2013), so we next examined the ability of methylone and its metabolites to interact with monoamine transporters in vitro. Table 3 reports the potency $\left(\mathrm{EC}_{50}\right)$ and efficacy (\% maximal) for each compound to stimulate release of $\left[{ }^{3} \mathrm{H}\right] \mathrm{MPP}^{+}$at DAT and NET and release of $\left[{ }^{3} \mathrm{H}\right] 5$-HT at SERT. In agreement with our previous findings, methylone acted as a fully efficacious substrate-type releaser at DAT, NET, and SERT, with roughly equal potencies at DAT and NET and slightly lower potency at SERT. MDC was a fully efficacious releaser and showed a selectivity profile similar to methylone. HHMC was a potent efficacious releaser at DAT and NET but weak at SERT. The dihydroxy metabolite was highly selective for the catecholamine transporters, exhibiting a DAT/SERT ratio of 155 . In contrast to the other compounds, HMMC was a weak releaser, with potencies $>5 \mu \mathrm{M}$ at all transporter sites.

\section{Effects of Methylone and its Metabolites In Vivo}

The findings from the in vitro transporter assays demonstrated that MDC and HHMC are potent and efficacious releasers. Thus we next utilized in vivo microdialysis in rat nucleus accumbens to examine the effects of iv administration of methylone, MDC, HHMC, and HMMC on neuro-

Table 2 Correlations Between Analyte Concentrations and Specific Pharmacodynamic Parameters

\begin{tabular}{|c|c|c|c|c|}
\hline Analytes & Parameter & Pearson's $r$ & $R^{2}$ & $p$ \\
\hline Methylone $(\mu g / l)$ & Behavioral score & 0.771 & 0.595 & $<0.001$ \\
\hline Methylone $(\mu g / l)$ & Temperature $\left({ }^{\circ} \mathrm{C}\right)$ & 0.126 & 0.016 & 0.619 (NS) \\
\hline $\operatorname{MDC}(\mu g / I)$ & Behavioral score & 0.867 & 0.752 & $<0.00$ I \\
\hline MDC ( $\mu g / l)$ & Temperature $\left({ }^{\circ} \mathrm{C}\right)$ & 0.235 & 0.055 & 0.168 (NS) \\
\hline $\mathrm{HHMC}(\mu \mathrm{g} / \mathrm{l})$ & Behavioral score & 0.660 & 0.435 & 0.003 \\
\hline $\mathrm{HHMC}(\mu g / l)$ & Temperature $\left({ }^{\circ} \mathrm{C}\right)$ & 0.281 & 0.079 & 0.259 (NS) \\
\hline HMMC $(\mu g / l)$ & Behavioral score & 0.416 & 0.173 & 0.086 (NS) \\
\hline HMMC $(\mu g / l)$ & Temperature $\left({ }^{\circ} \mathrm{C}\right)$ & 0.456 & 0.208 & 0.057 (NS) \\
\hline
\end{tabular}

Abbreviations: NS, nonsignificant; Pearson's $r$, correlation coefficient; $R^{2}$, goodness of fit for linear regression or $\mathrm{R}$ squared. chemistry and behavior. Figure 5 depicts the effects of iv administration of methylone and its metabolites on extracellular dopamine. Methylone produced dose-related elevations in dialysate dopamine $\left(\mathrm{F}_{1,99}=83.81, p<0.0001\right)$, with significant increases above saline control at the 1 and $3 \mathrm{mg} /$ $\mathrm{kg}$ doses. The maximal rise in dopamine was 2 -fold after $1 \mathrm{mg} / \mathrm{kg}$ and 3.5 -fold after $3 \mathrm{mg} / \mathrm{kg}$. MDC also elevated dopamine $\left(\mathrm{F}_{1,99}=44.60, p<0.0001\right)$, but the metabolite had less robust effects when compared with methylone. In contrast to MDC, neither HHMC nor HMMC altered extracellular dopamine concentrations after iv injection.

Figure 6 illustrates the effects of iv administration of methylone and its metabolites on extracellular 5-HT. Methylone produced robust dose-related elevations in dialysate 5 - $\mathrm{HT} \quad\left(\mathrm{F}_{1,99}=41.85, p<0.0001\right)$, with significant increases above saline control at both doses. The magnitude of 5-HT elevations reached 7- and 14-fold above baseline after the 1 and $3 \mathrm{mg} / \mathrm{kg}$ methylone doses, respectively. MDC also elevated 5-HT $\left(\mathrm{F}_{1,99}=61.71, p<0.0001\right)$, but the metabolite had somewhat smaller effects when compared with methylone, with maximal increases of 4- and 11-fold after the 1 and $3 \mathrm{mg} / \mathrm{kg}$ doses. Neither of the hydroxylated metabolites altered extracellular 5-HT concentrations after iv injection. The data in Figure 7 depict the effects of methylone, MDC, HHMC, and HMMC on locomotor activity. Methylone transiently stimulated motor activity $\left(\mathrm{F}_{1,99}=7.77, p<0.005\right)$, with significant increases at the first time point after 1 and $3 \mathrm{mg} / \mathrm{kg}$ doses. MDC also increased motor activity $\left(\mathrm{F}_{1,99}=7.17, p<0.01\right)$, but this effect reached statistical significance only after the $3 \mathrm{mg} / \mathrm{kg}$ dose. Neither HHMC nor HMMC affected motor activity after iv injection.

\section{DISCUSSION}

Methylone is a popular drug of abuse, yet few studies have addressed its PK and metabolism in animal models (Kamata et al, 2006; Lopez-Arnau et al, 2013). Here we examined the plasma PK profiles and pharmacodynamic effects for methylone and its phase I metabolites in conscious rats. There are three main findings from the present study. First, methylone is extensively metabolized in a manner similar to its structural analog MDMA, as illustrated by the formation of $O$-demethylenated metabolites (ie, HHMC and HMMC) and an $\mathrm{N}$-demethylated metabolite (ie, MDC). In general, plasma concentrations of methylone and its metabolites displayed more rapid kinetics when compared with MDMA (Baumann et al, 2009; Concheiro et al, 2014). Second, we

Table 3 Effects of Methylone, MDC, HHMC, and HMMC on the Release of $\left[^{3} \mathrm{H}\right] \mathrm{MPP}{ }^{+}$from DAT and NET, and $\left[^{3} \mathrm{H}\right] 5-\mathrm{HT}$ From SERT, in Rat Brain Synaptosomes

\begin{tabular}{|c|c|c|c|c|}
\hline Test drug & $\begin{array}{c}\mathrm{DAT} \text { release, } \mathrm{EC}_{50}, \mathrm{nM}_{ \pm} \mathrm{SD} \\
(\% \max )\end{array}$ & $\begin{array}{c}\text { NET release, } \mathrm{EC}_{50}, \mathrm{nM} \pm \mathrm{SD} \\
(\% \text { max })\end{array}$ & $\begin{array}{c}\text { SERT release, } \mathrm{EC}_{50}, \mathrm{nM}_{ \pm} \mathrm{SD} \\
(\% \text { max })\end{array}$ & DAT/SERT ratio \\
\hline Methylone & $203 \pm 31(100)$ & $164 \pm 28(95)$ & $708 \pm 72(102)$ & 3.5 \\
\hline $\mathrm{HHMC}$ & $90 \pm 12(92)$ & $110 \pm 22(89)$ & $14100 \pm 6700(75)$ & 155 \\
\hline HMMC & $5840 \pm 1460(98)$ & $6340 \pm 2540(100)$ & $7210 \pm 2590(70)$ & 1.2 \\
\hline
\end{tabular}

Data are $\mathrm{EC}_{50}$ expressed as $\mathrm{nM}$ concentrations (mean $\pm \mathrm{SD}$ ) for $\mathrm{N}=3$ experiments performed in triplicate. \% Max indicates efficacy compared with saturating concentrations of tyramine as described in Materials and Methods section. DAT/SERT ratio = I/(DAT EC ${ }_{50}$ ) divided by I/(SERT EC $\mathrm{C}_{50}$ ); higher values reflect greater DAT selectivity. 

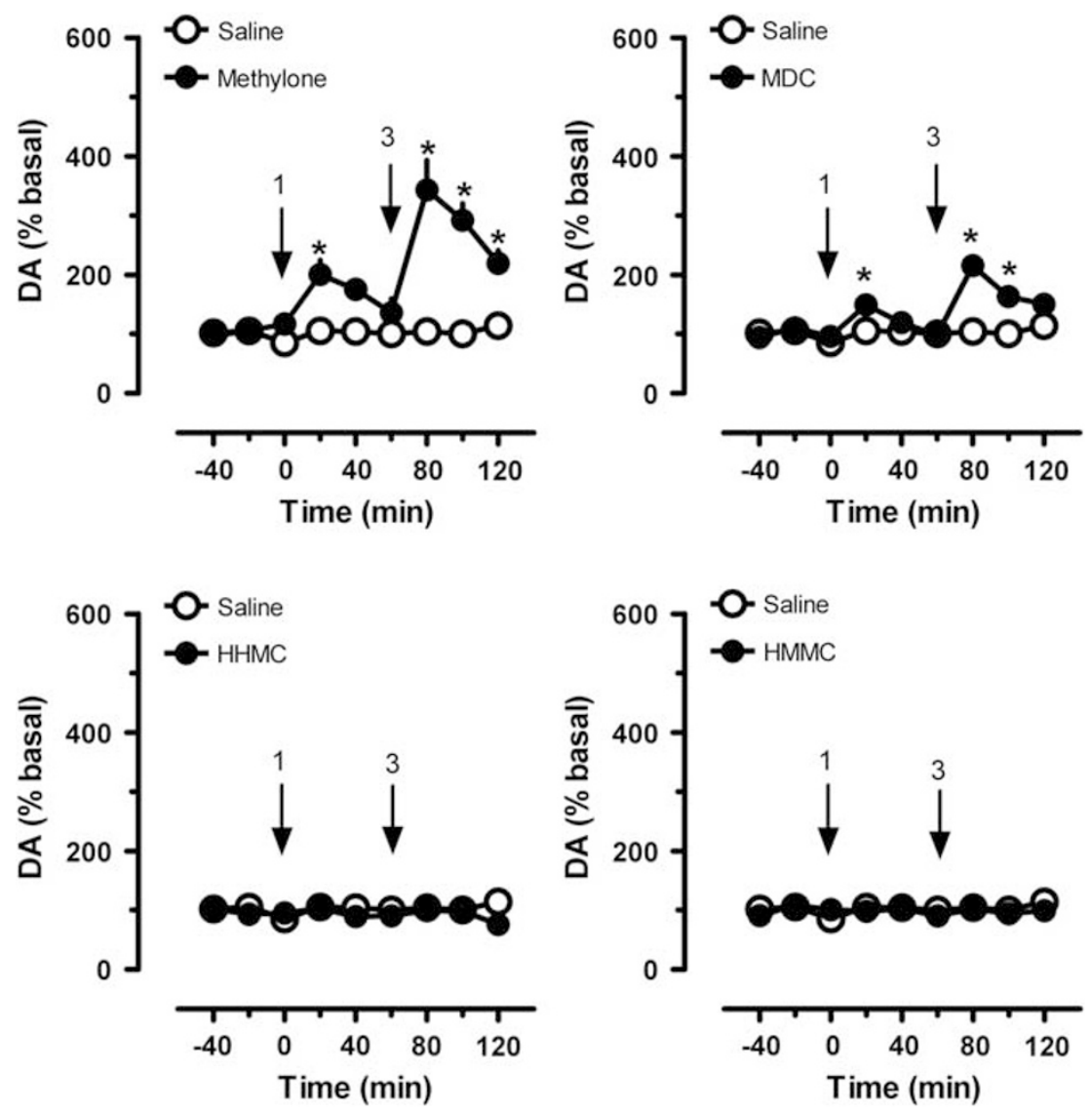

Figure 5 Dose-response effects of methylone, MDC, HHMC, and HMMC on extracellular dopamine (DA) in male rats undergoing in vivo microdialysis in nucleus accumbens. Drug-treated rats received iv injections of I mg/ $/ \mathrm{kg}$ at time 0 , followed by $3 \mathrm{mg} / \mathrm{kg} 60 \mathrm{~min}$ later. Control rats received iv saline injections $(\mathrm{l} \mathrm{ml} / \mathrm{kg}$ ) on the same schedule. Data are mean \pm SEM for $N=6 / 7$ rats per group, expressed as a percentage of preinjection baseline values (\% basal). Mean basal dialysate DA concentration for all the treatment groups was $1.55 \pm 0.35 \mathrm{pg} / 5 \mu \mathrm{l}(\mathrm{N}=34 \mathrm{rats}) . * 0<0.05$ vs saline control at the corresponding time point (Bonferroni's post hoc test).

present the first in vivo evidence for non-linear PK after high-dose methylone administration, which is characterized by increases in circulating concentrations of methylone and MDC that are greater than dose-proportional. Finally, the metabolites MDC and HHMC are potent substrate-type releasers at monoamine transporters as assessed in vitro, but only MDC affects brain neurochemistry and locomotor behavior when administered in vivo. Taken together, the findings indicate that MDC is the only metabolite that could contribute to the psychoactive effects of systemically administered methylone, but this metabolite is found at much lower concentrations than the parent compound.

One of the primary aims of our study was to examine methylone PKs at sc doses in rats that are relevant to doses abused by humans (eg, 1-3 mg/kg, oral dosing) (see https:// www.erowid.org/chemicals/methylone/methylone_dose.shtml for human self-reported dosages). Although dose extrapolations across species are difficult to make because no controlled studies have examined methylone administration in humans, we found methylone $C_{\max }$ values of 620,1410 , and $3170 \mu \mathrm{g} / \mathrm{l}$ after sc doses of 3,6 , and $12 \mathrm{mg} / \mathrm{kg}$, respectively. These plasma concentrations from rats fall within the range of values $(60-3400 \mu \mathrm{g} / \mathrm{l})$ detected in human blood specimens reported from case studies, which represent the sole point of comparison between rodent and human data (Barrios et al,
2015; Carbone et al, 2013; Cawrse et al, 2012; Knoy et al, 2014; Kovacs et al, 2012; McIntyre et al, 2013).

Methylone exhibited rapid kinetics compared with its structural analog MDMA, with $T_{\max }$ occurring at $15 \mathrm{~min}$ as opposed to 36,54 , and $66 \mathrm{~min}$ for $2.5,5$, and $10 \mathrm{mg} / \mathrm{kg}$ MDMA, respectively (Concheiro et al, 2014). Owing to the rapid PKs of methylone after sc administration, it is plausible that $T_{\max }$ may have occurred even earlier than $15 \mathrm{~min}$, if specimens had been collected earlier. MDC reached peak concentrations more slowly than methylone and persisted for longer. Plasma concentrations of HHMC reached $T_{\max }$ within $1 \mathrm{~h}$, but more quickly than HMMC, which is consistent with the formation of HMMC from the diol metabolite, HHMC (see Figure 1). Importantly, in agreement with the past metabolic analyses of methylone in urine (Kamata et al, 2006), HMMC was the predominant metabolite in plasma. The relatively slow formation and clearance of HMMC make it a potential target for toxicological identification of methylone exposure.

It is well established that MDMA displays non-linear PKs in rats and humans (Baumann et al, 2009; Chu et al, 1996; Concheiro et al, 2014; de la Torre et al, 2000; Kolbrich et al, 2008) owing to inhibition of its own metabolism (Heydari et al, 2004; Wu et al, 1997). By contrast, Lopez-Arnau et al (2013) found no evidence for non-linear PKs in rats after oral 

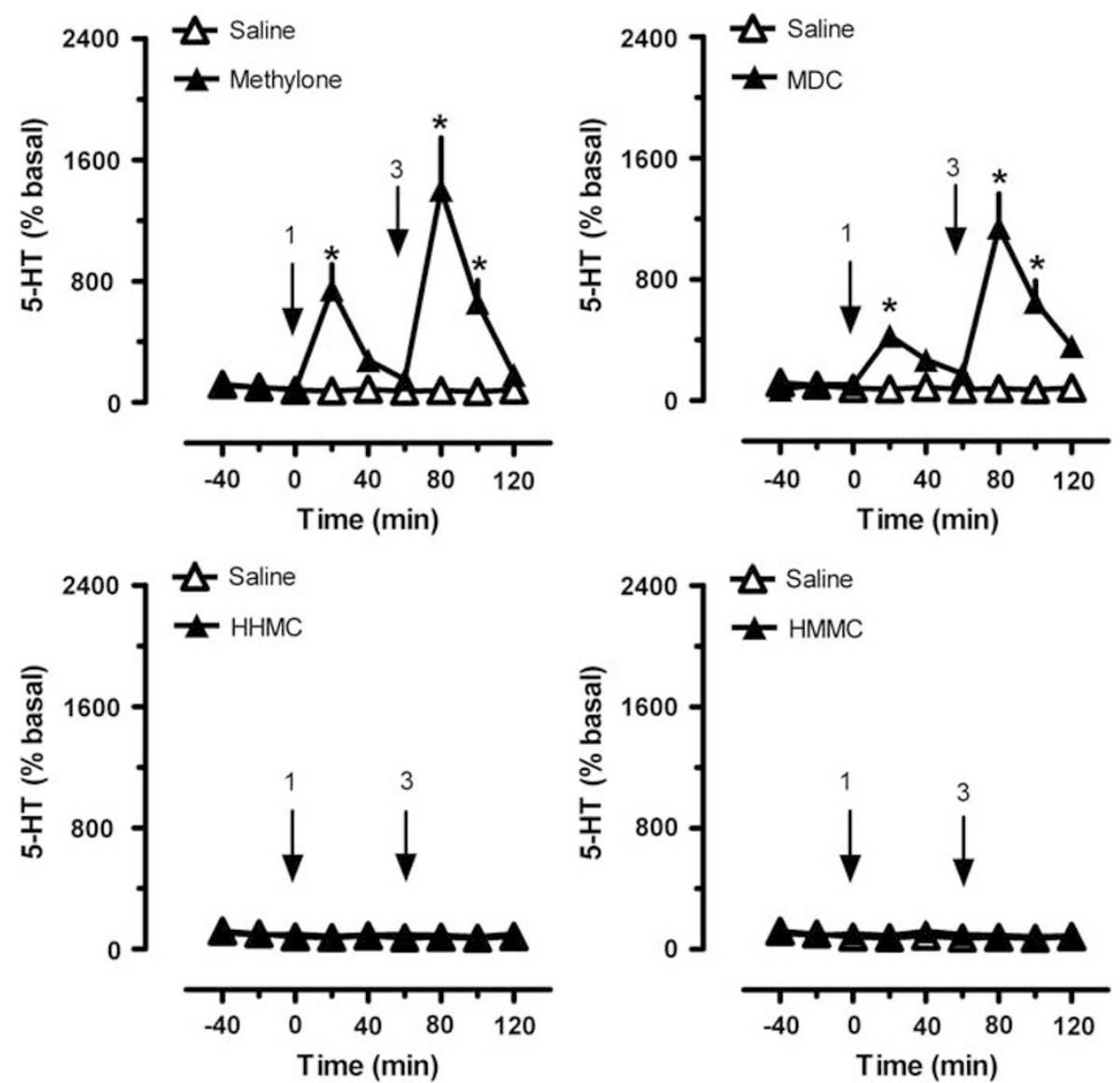

Figure 6 Dose-response effects of methylone, MDC, HHMC, and HMMC on extracellular serotonin (5-HT) in male rats undergoing in vivo microdialysis in nucleus accumbens. Drug-treated rats received iv injections of I mg/kg at time 0 , followed by $3 \mathrm{mg} / \mathrm{kg} 60 \mathrm{~min}$ later. Control rats received iv saline injections $(\mathrm{I} \mathrm{ml} / \mathrm{kg}$ ) on the same schedule. Data are mean \pm SEM for $\mathrm{N}=6 / 7$ rats per group, expressed as a percentage of preinjection baseline values (\% basal). Mean basal dialysate $5-\mathrm{HT}$ concentration for all the groups was $0.42 \pm 0.1 \mathrm{I} \mathrm{pg} / 5 \mu \mathrm{l}(\mathrm{N}=34 \mathrm{rats})$. $* \mathrm{p}<0.05$ vs saline control at the corresponding time point (Bonferroni's post hoc test).

administration of methylone at 15 and $30 \mathrm{mg} / \mathrm{kg}$. For linear kinetics to be observed in the present study, an increase in dose from 3 to $6 \mathrm{mg} / \mathrm{kg}$ should produce a doubling of AUC values for methylone and its metabolites, while an increase from 3 to $12 \mathrm{mg} / \mathrm{kg}$ should produce a 4 -fold increase in AUC values. The data in Figure 3 clearly demonstrate that plasma concentrations of methylone and MDC increase more than expected based on the doses administered, providing an indication of non-linear accumulation for these analytes in plasma. Methylone inhibits human CYP2D6 in vitro (Dinger et al, 2016; Pedersen et al, 2013), and the present non-linear increases in plasma methylone and MDC seem to agree with this observation. It should be mentioned that non-linear kinetics resulting from inhibition of CYP2D1 (ie, the rat isoform of CYP2D6 responsible for methylone O-demethylenation) should result in appreciable decreases in the formation of HHMC and HMMC (see Concheiro et al, 2014). However, Figure 3 illustrates that AUC values for HHMC and HMMC were within the expected range as dose increased, not less than predicted. Thus additional research utilizing a broader range of methylone doses will be needed to definitely demonstrate the phenomenon of non-linear PK for methylone.
Our PK study employed rats bearing indwelling iv catheters, which allowed repeated stress-free blood sampling, along with measurement of locomotor behavior and core temperature by non-invasive methods. The behavioral activity scoring system used for our experiments is sensitive to dose-dependent changes in locomotor activation produced by psychomotor stimulants, such as cocaine (Baumann et al, 1993; Kalivas et al, 1988). Specifically, as the dose of drug is increased, the predominant behaviors change from exploratory ambulation and rearing to repetitive stereotypic movements. We found that methylone produced dose-related increases in motor activity with concomitant decreases in temperature. Methylone-induced locomotor activation was positively correlated with plasma concentrations of methylone, MDC, and HHMC, whereas core temperature failed to correlate with any analyte measured (see Table 2). Overall, the PK and pharmacodynamic results suggested that MDC and HHMC might contribute significantly to behavioral effects, but not temperature changes, produced by systemically administered methylone.

It is now well established that methylone acts as a substrate-type releaser at DAT, NET, and SERT in rat brain tissue and in cells expressing human transporters (Baumann et al, 2012; Eshleman et al, 2013; Simmler et al, 2013). Thus 

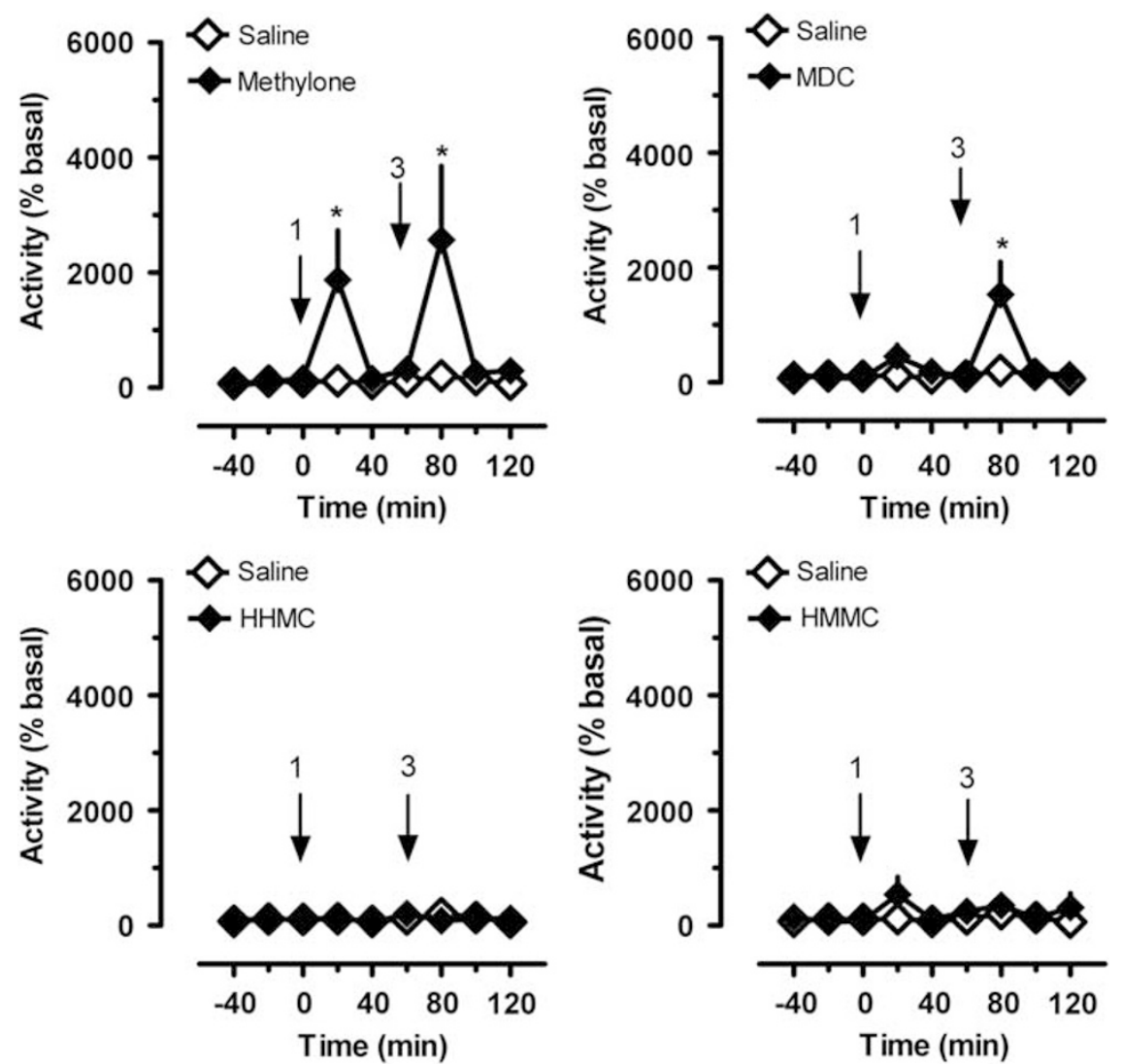

Figure 7 Dose-response effects of methylone, MDC, HHMC, and HMMC on forward locomotion (activity) in male rats undergoing in vivo microdialysis in nucleus accumbens. Drug-treated rats received iv injections of I mg/kg at time 0, followed by $3 \mathrm{mg} / \mathrm{kg} 60 \mathrm{~min}$ later. Control rats received iv saline injections $(\mathrm{l} \mathrm{ml} / \mathrm{kg}$ ) on the same schedule. Data are mean \pm SEM for $N=6 / 7$ rats per group, expressed as a percentage of preinjection baseline values (\% basal). Mean basal activity was $86 \pm 22 \mathrm{~cm} / 20$ min bin ( $N=34$ rats). $* p<0.05$ vs saline control at the corresponding time point (Bonferroni's post hoc test).

we wished to examine the effects of methylone metabolites using in vitro transporter release assays in rat brain synaptosomes. In agreement with previous findings, methylone acted as a potent and efficacious releaser, with slightly higher potency at DAT and NET as compared with SERT (Baumann et al, 2012). MDC had a similar release profile but was weaker at all three transporters. The data reported here for MDC differ somewhat from findings with 3,4-methylenedioxyamphetamine (MDA), the analogous $N$-demethylated metabolite of MDMA. We and others have shown that MDA and MDMA display nearly identical potency and selectivity as substrate-type releasers at monoamine transporters in vitro (McKenna et al, 1991; Sandtner et al, 2016; Wichems et al, 1995). Interestingly, HHMC was found to be a potent and selective substrate for DAT and NET, with a DAT/SERT ratio of 155 in vitro. In fact, HHMC was more potent than methylone as a releaser at DAT and NET. By contrast, HMMC was very weak at all transporters.

Because we found that MDC and HHMC were potent efficacious releasers at monoamine transporters, we sought to examine the neurochemical and behavioral effects of these metabolites when administered in vivo. Consistent with previous work (Baumann et al, 2012; Schindler et al, 2016), we found that methylone produced dose-related elevations in extracellular dopamine and 5-HT in rat nucleus accumbens, with larger effects on extracellular 5-HT. Importantly, the iv doses of methylone tested here in microdialysis experiments are in the range of those self-administered by rats (Schindler et al, 2016; Vandewater et al, 2015; Watterson et al, 2012). Administration of MDC increased dopamine and 5-HT as well, but weakly compared with methylone. The microdialysis data with MDC are generally consistent with its lower potency at DAT and SERT but differ from results obtained with MDA (Baumann et al, 2007; Kankaanpaa et al, 1998; Nash and Nichols, 1991). For example, Kankaanpaa et al (1998) showed that MDA administration to rats induced elevations in extracellular dopamine and 5-HT in the nucleus accumbens that were greater than those produced by MDMA. Dal Cason et al (1997) examined the discriminative stimulus properties of MDC and reported the compound fully substitutes for the stimulus cue in MDMA-trained rats but not in amphetamine-trained rats, consistent with the notion that MDC has somewhat greater effects on 5-HT systems in vivo as compared with dopamine systems (Dal Cason et al, 1997).

Surprisingly, we found that neither HHMC nor HMMC altered dialysate neurotransmitter concentrations after iv administration at the doses tested. Examination of the locomotor behavior during microdialysis sampling demonstrated that methylone and MDC stimulated activity but HHMC and HMMC did not. When combined with the in vitro results, the microdialysis data suggest that HHMC 
may not cross the blood-brain barrier, perhaps owing to its increased polarity relative to methylone. Indeed, the total polar surface area for HHMC is 69.55 as compared with 47.57 for methylone (http://www.molinspiration.com/cgibin/properties). It seems feasible that administration of higher doses of HHMC might produce centrally mediated effects, but this possibility requires further study. Additionally, as CYP enzymes are present in brain tissue, HHMC could be produced locally in the brain after systemic administration of methylone. In previous studies, we found that 3,4-dihydroxymethamphetamine, the $O$-demethylenated metabolite of MDMA, does not appear to penetrate into the brain but has powerful cardiovascular effects in vivo (Schindler et al, 2014). Thus further studies are needed to examine the possible cardiovascular effects of HHMC, based on its potent releasing activity at NET.

In conclusion, we report the first plasma $\mathrm{PK}$ profiles for methylone and its metabolites in conscious freely moving rats and provide evidence for non-linear accumulation of methylone and MDC after high-dose administration. The metabolites MDC and HHMC are potent efficacious substrate-type releasers at monoamine transporters as assessed in vitro, but only MDC produces centrally mediated neurochemical and behavioral changes when administered in vivo. HMMC is the most predominant and persistent metabolite of methylone, making HMMC a good target for forensic drug testing to confirm methylone exposure, expanding the window of detection. Further studies are necessary to more fully explore the phenomenon of nonlinear PKs and its associated pharmacodynamic consequences after high-dose methylone administration.

\section{FUNDING AND DISCLOSURE}

This research was generously supported by the Intramural Research Program of the National Institute on Drug Abuse, National Institutes of Health. The authors declare no conflicts of interest.

\section{REFERENCES}

Barrios L, Grison-Hernando H, Boels D, Bouquie R, Monteil-Ganiere C, Clement R (2015). Death following ingestion of methylone. Int J Legal Med 130: 381-385.

Baumann MH, Ayestas MA Jr., Partilla JS, Sink JR, Shulgin AT, Daley PF et al (2012). The designer methcathinone analogs, mephedrone and methylone, are substrates for monoamine transporters in brain tissue. Neuropsychopharmacology 37: 1192-1203.

Baumann MH, Partilla JS, Lehner KR (2013). Psychoactive 'bath salts': not so soothing. Eur J Pharmacol 698: 1-5.

Baumann MH, Raley TJ, Partilla JS, Rothman RB (1993). Biosynthesis of dopamine and serotonin in the rat brain after repeated cocaine injections: a microdissection mapping study. Synapse 14: 40-50.

Baumann MH, Wang X, Rothman RB (2007). 3,4-Methylenedioxymethamphetamine (MDMA) neurotoxicity in rats: a reappraisal of past and present findings. Psychopharmacology 189: 407-424.

Baumann MH, Zolkowska D, Kim I, Scheidweiler KB, Rothman RB, Huestis MA (2009). Effects of dose and route of administration on pharmacokinetics of (+ or -)-3,4-methylenedioxymethamphetamine in the rat. Drug Metab Dispos 37: 2163-2170.
Carbone PN, Carbone DL, Carstairs SD, Luzi SA (2013). Sudden cardiac death associated with methylone use. Am J Forensic Med Pathol 34: 26-28.

Cawrse BM, Levine B, Jufer RA, Fowler DR, Vorce SP, Dickson AJ et al (2012). Distribution of methylone in four postmortem cases. J Anal Toxicol 36: 434-439.

Chu T, Kumagai Y, DiStefano EW, Cho AK (1996). Disposition of methylenedioxymethamphetamine and three metabolites in the brains of different rat strains and their possible roles in acute serotonin depletion. Biochem Pharmacol 51: 789-796.

Concheiro M, Baumann MH, Scheidweiler KB, Rothman RB, Marrone GF, Huestis MA (2014). Nonlinear pharmacokinetics of (+/-)3,4-methylenedioxymethamphetamine (MDMA) and its pharmacodynamic consequences in the rat. Drug Metab Dispos 42: 119-125.

Dal Cason TA, Young R, Glennon RA (1997). Cathinone: an investigation of several $\mathrm{N}$-alkyl and methylenedioxy-substituted analogs. Pharmacol Biochem Behav 58: 1109-1116.

de la Torre R, Farre M (2004). Neurotoxicity of MDMA (ecstasy): the limitations of scaling from animals to humans. Trends Pharmacol Sci 25: 505-508.

de la Torre R, Farre M, Ortuno J, Mas M, Brenneisen R, Roset PN et al (2000). Non-linear pharmacokinetics of MDMA ('ecstasy') in humans. Br J Clin Pharmacol 49: 104-109.

Dinger J, Meyer MR, Maurer HH (2016). In vitro cytochrome P450 inhibition potential of methylenedioxy-derived designer drugs studied with a two-cocktail approach. Arch Toxicol 90: 305-318.

Drug Enforcement Administration DoJ (2011). Schedules of controlled substances: temporary placement of three synthetic cathinones in Schedule I. Final Order. Fed Regist 76: 65371-65375.

Drug Enforcement Administration DoJ (2013). Establishment of drug codes for 26 substances. Final rule. Fed Regist 78: 664-666.

Ellefsen K, Concheiro M, Suzuki M, Rice K, Elmore J, Baumann M et al (2015). Quantification of methylone and metabolites in rat and human plasma by liquid chromatography-tandem mass spectrometry. Forensic Toxicol 33: 202-212.

Eshleman AJ, Wolfrum KM, Hatfield MG, Johnson RA, Murphy KV, Janowsky A (2013). Substituted methcathinones differ in transporter and receptor interactions. Biochem Pharmacol 85: 1803-1815.

Glennon RA (2014). Bath salts, mephedrone, and methylenedioxypyrovalerone as emerging illicit drugs that will need targeted therapeutic intervention. Adv Pharmacol 69: 581-620.

Grecco GG, Sprague JE (2016). Impact of functional group modifications on designer phenethylamine induced hyperthermia. Chem Res Toxicol 29: 871-878.

Heydari A, Yeo KR, Lennard MS, Ellis SW, Tucker GT, Rostami-Hodjegan A (2004). Mechanism-based inactivation of CYP2D6 by methylenedioxymethamphetamine. Drug Metab Dispos 32: 1213-1217.

Kalivas PW, Duffy P, DuMars LA, Skinner C (1988). Behavioral and neurochemical effects of acute and daily cocaine administration in rats. J Pharmacol Exp Ther 245: 485-492.

Kamata HT, Shima N, Zaitsu K, Kamata T, Miki A, Nishikawa M et al (2006). Metabolism of the recently encountered designer drug, methylone, in humans and rats. Xenobiotica 36: 709-723.

Kankaanpaa A, Meririnne E, Lillsunde P, Seppala T (1998). The acute effects of amphetamine derivatives on extracellular serotonin and dopamine levels in rat nucleus accumbens. Pharmacol Biochem Behav 59: 1003-1009.

Kiyatkin EA, Kim AH, Wakabayashi KT, Baumann MH, Shaham Y (2015). Effects of social interaction and warm ambient temperature on brain hyperthermia induced by the designer drugs methylone and MDPV. Neuropsychopharmacology 40: 436-445. 
Knoy JL, Peterson BL, Couper FJ (2014). Suspected impaired driving case involving alpha-pyrrolidinovalerophenone, methylone and ethylone. J Anal Toxicol 38: 615-617.

Kolbrich EA, Goodwin RS, Gorelick DA, Hayes RJ, Stein EA, Huestis MA (2008). Plasma pharmacokinetics of 3,4-methylenedioxymethamphetamine after controlled oral administration to young adults. Ther Drug Monit 30: 320-332.

Kovacs K, Toth AR, Kereszty EM (2012). [A new designer drug: methylone related death]. Orvosi Hetilap 153: 271-276.

Lopez-Arnau R, Martinez-Clemente J, Carbo M, Pubill D, Escubedo E, Camarasa J (2013). An integrated pharmacokinetic and pharmacodynamic study of a new drug of abuse, methylone, a synthetic cathinone sold as 'bath salts'. Prog Neuropsychopharmacol Biol Psychiatry 45: 64-72.

Lopez-Arnau R, Martinez-Clemente J, Pubill D, Escubedo E, Camarasa J (2014). Serotonergic impairment and memory deficits in adolescent rats after binge exposure of methylone. J Psychopharmacol 28: 1053-1063.

McIntyre IM, Hamm CE, Aldridge L, Nelson CL (2013). Acute methylone intoxication in an accidental drowning-a case report. Forensic Sci Int 231: e1-e3.

McKenna DJ, Guan XM, Shulgin AT (1991). 3,4-Methylenedioxyamphetamine (MDA) analogues exhibit differential effects on synaptosomal release of $3 \mathrm{H}$-dopamine and $3 \mathrm{H}-5-$ hydroxytryptamine. Pharmacol Biochem Behav 38: 505-512.

Nash JF, Nichols DE (1991). Microdialysis studies on 3,4methylenedioxyamphetamine and structurally related analogues. Eur J Pharmacol 200: 53-58.

Pedersen AJ, Petersen TH, Linnet K (2013). In vitro metabolism and pharmacokinetic studies on methylone. Drug Metab Dispos 41: 1247-1255.

Ridpath A, Driver CR, Nolan ML, Karpati A, Kass D, Paone D et al (2014). Illnesses and deaths among persons attending an electronic dance-music festival - New York City, 2013. MMWR Morb Mortal Wkly Rep 63: 1195-1198.

Rothman RB, Baumann MH, Dersch CM, Romero DV, Rice KC, Carroll FI et al (2001). Amphetamine-type central nervous system stimulants release norepinephrine more potently than they release dopamine and serotonin. Synapse 39: 32-41.

Sandtner W, Stockner T, Hasenhuetl PS, Partilla JS, Seddik A, Zhang YW et al (2016). Binding mode selection determines the action of ecstasy homologs at monoamine transporters. Mol Pharmacol 89: 165-175.

Schindler CW, Thorndike EB, Blough BE, Tella SR, Goldberg SR, Baumann MH (2014). Effects of 3,4-methylenedioxymethamphetamine (MDMA) and its main metabolites on cardiovascular function in conscious rats. Br J Pharmacol 171: 83-91.

Schindler CW, Thorndike EB, Goldberg SR, Lehner KR, Cozzi NV, Brandt SD et al (2016). Reinforcing and neurochemical effects of the 'bath salts' constituents 3,4-methylenedioxypyrovalerone (MDPV) and 3,4-methylenedioxy-N-methylcathinone (methylone) in male rats. Psychopharmacology 233: 1981-1990.

Simmler LD, Buser TA, Donzelli M, Schramm Y, Dieu LH, Huwyler J et al (2013). Pharmacological characterization of designer cathinones in vitro. Br J Pharmacol 168: 458-470.

Vandewater SA, Creehan KM, Taffe MA (2015). Intravenous selfadministration of entactogen-class stimulants in male rats. Neuropharmacology 99: 538-545.

Warrick BJ, Wilson J, Hedge M, Freeman S, Leonard K, Aaron C (2012). Lethal serotonin syndrome after methylone and butylone ingestion. J Med Toxicol 8: 65-68.

Watterson LR, Hood L, Sewalia K, Tomek SE, Yahn S, Johnson CT et al (2012). The reinforcing and rewarding effects of methylone, a synthetic cathinone commonly found in 'bath salts'. J Addict Res Ther Suppl 9: pii 002.

Wichems CH, Hollingsworth CK, Bennett BA (1995). Release of serotonin induced by 3,4-methylenedioxymethamphetamine (MDMA) and other substituted amphetamines in cultured fetal raphe neurons: further evidence for calcium-independent mechanisms of release. Brain Res 695: 10-18.

Wu D, Otton SV, Inaba T, Kalow W, Sellers EM (1997). Interactions of amphetamine analogs with human liver CYP2D6. Biochem Pharmacol 53: 1605-1612. 